\title{
Serviços de Convivência e Fortalecimento de Vínculos na Relação Família e Sociedade
}

\author{
Antônia Luzinete de Souza ${ }^{1}$; Leonardo Manuel das Neves Rocha ${ }^{2}$
}

\begin{abstract}
Resumo: A partir da Constituição de 1988 os direitos dos cidadãos foram ampliados, sendo incluídos nestes os direitos sociais. Assim as políticas voltadas para assistência social sofreram transformações, principalmente à partir de 2005 com a criação do SUAS (Sistema Único de Assistência Social), que modificou a elaboração e execução das políticas públicas no país. Verifica-se então que com a descentralização modificou o processo de gestão das políticas públicas atuais, principalmente no destino dos recursos e na qualidade da assistência. Sendo assim verificou-se também a grande importância da atuação do gestor público municipal neste contexto. A principal função dos CRAS é proporcionar o fortalecimento da capacidade protetora das famílias referenciadas, sua relação no contexto familiar e entre a comunidade. A presente dissertação tem como intuito apresentar as ações desenvolvidas nestes respectivos campos de estágio na busca pela construção dos vínculos familiares e comunitários, considerando que isto se coloca como um desafio ao profissional do serviço social e aos demais trabalhadores do SUAS. Esse estudo teve por objetivo averiguar a história e a realidade de algumas famílias participantes dos grupos de convivência dos CRAS procurando perceber até que ponto, os objetivos dos SCFV, se consolidam no cotidiano dessas famílias dentro e fora do espaço do CRAS.
\end{abstract}

Palavras Chave: CRAS, Políticas Públicas de Assistência Social, Serviço de Convivência, Protagonismo.

\section{Living Services and Strengthening Linkages in Family Relations and Society}

\begin{abstract}
Since the 1988 Constitution, citizens' rights have been expanded, including social rights. Thus the facing social assistance policies have been transformed, mainly from 2005 with the creation of SUAS (Single Social Assistance System), which modified the development and implementation of public policies in the country. It is verified that with the decentralization it modified the process of management of the current public policies, mainly in the destiny of the resources and in the quality of the assistance. Thus, it was also verified the great importance of the performance of the municipal public manager in this context. The main function of CRAS is to provide the strengthening of the protective capacity of referenced families, their relationship in the family context and among the community. The purpose of this dissertation is to present the actions developed in these respective fields of study in the search for the construction of family and community ties, considering that this poses as a challenge to the social service professional and other SUAS workers. The objective of this study was to investigate the history and reality of some families participating in the CRAS cohabitation groups, seeking to understand the extent to which the SCFV objectives are consolidated in the daily life of these families within and outside the CRAS space.
\end{abstract}

Keywords: CRAS, Public Policies of Social Assistance, Coexistence Service, Protagonism.

\section{Introdução}

Segundo o relatório de Desenvolvimento Humano (2000), a pobreza é um fenômeno multidimensional que não se restringe apenas aos aspectos sociais econômicos com os quais é com frequência identificados.

\footnotetext{
${ }^{1}$ Mestre em Ciências da Educação pela Universidade Lusófona de Humanidades e Tecnologia - Lisboa, Portugal.

E-mail: alnenem@hotmail.com

${ }^{2}$ Orientador no Programa de Mestrado em Ciências da Educação da Universidade Lusófona de Humanidades e Tecnologia - Lisboa/PT. 
Id on Line Revista Multidisciplinar e de Psicologia

Id on Line Multidisciplinary and Psycology Journal

Por essa razão as medidas voltadas ao enfrentamento das situações de vulnerabilidades sociais não ultrapassam o campo dos programas das políticas sociais, quase sempre traçados sem a participação dos maiores interessados.

Poucos estudiosos enfocam a dimensão política da pobreza abordando os processos históricos de destituição de poder da população submetida a essa condição, assim como a falta de representação desse contingente nas várias esferas de decisão do estado (BRANCO, 2001).

É nesse contexto que residem os aspectos primordiais para entender tanto a pobreza socioeconômica dos brasileiros de origens diversas, quanto a persistência dessa situação no tempo. O centro da questão estaria no confronto entre as minorias que comandam e a maioria que sustentam os privilégios daquelas que comandam.

Ao tratar da educação, Freire (1997), cunha o termo política como o confronto entre incluídos e excluídos, em que enquanto os oprimidos esperarem ser libertos pelos opressores, não serão construtores e gestores de sua própria vida, já que são desprovidos não apenas de bens materiais, mas sobretudo da capacidade de se governar. Os oprimidos não podem ser somente objetos de distribuição de bens na condição de simples beneficiários. As estratégias de combate a pobreza devem estimular as pessoas pobres a tornar-se sujeitos de alternativas a pobreza de renda soma-se a pobreza política. É fundamental que sejam elaboradas e implementadas políticas públicas envolvendo Estado e Sociedade para proteger a vida e a integridade física desses jovens e para oferecer perspectivas de plena realização de seu desenvolvimento. Eles são parte do futuro urge erradicar a pobreza a partir de um contexto mais sistêmico e abrangente, no qual o norte será o desenvolvimento humano da população mais vulnerável e demais seguimentos excluídos. As famílias que não tem condições, de atender as necessidades básicas de seus filhos vivem um grande desafio quando a elas não são acessíveis políticas públicas que assegurem condições mínima de vida digna: emprego, renda e apoio (OLIVEIRA et al, 2014).

O presente estudo apresenta uma investigação empírica acerca da trajetória da política de assistência social, ao longo desses 27 anos. Sabemos que muitos são os problemas que afetam as famílias nos diferentes contextos sociais. Realizar uma reflexão sobre os direitos conquistados, mesmo após a sua inclusão na constituição federal de 1988, onde assistência adquiriu o status de direito. Existe vários estudos que tratam das políticas de assistência social e dos programas e serviços ofertados nos (SCFV) bem como de todo um contexto que envolve as famílias que se encontram em situação de pobreza e vulnerabilidade social. Mas os objetivos 
Id on Line Revista Multidisciplinar e de Psicologia

Id on Line Multidisciplinary and Psycology Journal

desses programas acontecem de forma tímida, pois são inúmeras as barreiras e problemas estruturais elencadas aqui pelos diversos autores pesquisados.

\section{Marcos legais da Política de Ação Social}

Os marcos legais da Assistência Social expressam mudança de paradigma na área definida como política pública com capilaridade nacional e como direito social, fundado no princípio democrático do controle social e da descentralização política e administrativa, cujas ações, visando superar a fragmentação e segmentação, tomam a família como estratégia de organização dos serviços, como um dos sujeitos beneficiários da assistência social e alvo de trabalho sócio educativo.

\footnotetext{
Entre seus beneficiários destacam-se, além da família, cidadãos e grupos que se encontram em situação de vulnerabilidade e risco, tais como: Famílias e indivíduos com perda ou fragilidade de vínculos de afetividade, pertencimento e sociabilidade; ciclos de vida; identidades estigmatizadas em termos étnicos, cultural e sexual; desvantagem a pessoal resultante de deficiência; exclusão pela pobreza e/ou no acesso às demais políticas públicas; uso de substâncias psicoativas; diferentes formas de violência advinda do núcleo familiar, grupos e indivíduos; inserção precária ou não inserção no mercado de trabalho formal e informal; estratégias e alternativas diferenciadas de sobrevivência que podem representar risco pessoal e social (BRASIL, 2004, p. 33)
}

Essa definição é expressiva das mudanças na área; a política de Assistência Social, enquanto política de Estado constitui-se "como estratégia fundamental no combate à pobreza, à discriminação, às vulnerabilidades e à subalternidade econômica, cultural e política em que vive grande parte da população brasileira" (YAZBEK, 2008, p. 20-21).

\section{Centro de Referência e Assistência Social-CRAS}

O país tem 13.659 unidades prestadoras de serviços de assistência social em atividade. O número é 7,6\% menor do que o observado em 2013, quando foram registradas 14.791 unidades ativas. Os dados são da Pesquisa de Entidades de Assistência Social Privadas sem Fins Lucrativos no Brasil (PEAS) 2014-2015, do Instituto Brasileiro de Geografia e Estatística 
Id on Line Revista Multidisciplinar e de Psicologia

Id on Line Multidisciplinary and Psycology Journal

(IBGE). O Centro de Referência de Assistência Social (CRAS) é uma unidade pública estatal descentralizada da Política Nacional de Assistência Social PNAS). O CRAS, atua como a principal porta de entrada do Sistema Único de Assistência Social (Suas), dada sua capilaridade nos territórios e é responsável pela organização e oferta de serviços da Proteção Social Básica nas áreas de vulnerabilidade e risco social. Além de ofertar serviços e ações de proteção básica, o CRAS, possui a função de gestão territorial da rede de assistência social básica, promovendo a organização e articulação das unidades a ele referenciadas e o gerenciamento dos processos nele envolvidos (NETTO, 1996; ALENCAR et al, 2013).

Para Parente (2015),

\begin{abstract}
O principal serviço ofertado pelo CRAS é o Serviço de Proteção e Atendimento Integral à Família (PAIF), cuja execução é obrigatória e exclusiva. A Proteção Social Básica, são ações de caráter preventivo seu objetivo é fortalecer os laços familiares e comunitários, prevenindo situações de risco por meio do desenvolvimento de potencialidades e aquisições e o fortalecimento de vínculos familiares e comunitários. Destina-se à população que vive em situação de fragilidade decorrente da pobreza, ausência de renda, acesso precário ou nulo aos serviços públicos ou fragilização de vínculos afetivos (discriminações etárias, étnicas, de gênero ou por deficiências, dentre outras). (PARENTE, 2015, p. 09)
\end{abstract}

Essa Proteção prevê o desenvolvimento de serviços, programas e projetos locais de acolhimento, convivência e socialização de famílias e de indivíduos, conforme identificação da situação de vulnerabilidade apresentada. Esses serviços e programas deverão incluir as pessoas com deficiência e ser organizados em rede, de modo a inseri-las nas diversas ações ofertadas.

Os Benefícios Eventuais e os Benefícios de Prestação Continuada (BPC) compõem a Proteção Social Básica, dada a natureza de sua realização. A Proteção Social de Média Complexidade - são ações destinadas a situações onde os direitos do indivíduo da família já foram violados, com atendimento individualizado e monitoramento sistêmico.

O programa de atenção integral a família (PAINF) consiste em um trabalho de caráter continuado que visa fortalecer a função protetiva das famílias, prevenindo a ruptura de vínculos, promovendo o acesso e usufruto de direitos e contribuindo para a serviços sócio assistenciais, como o Programa Nacional de Promoção do Acesso ao Mundo do TrabalhoACESSUAS/TRABALHO, que busca a autonomia das famílias usuárias da política de assistência social, por meio do incentivo e da mobilização à integração ao mundo do trabalho. A Proteção Social Básica atua por intermédio de diferentes unidades. Dentre elas, destacam-se 
Id on Line Revista Multidisciplinar e de Psicologia

Id on Line Multidisciplinary and Psycology Journal

os Centros de Referência de Assistência Social (CRAS) e a rede de serviços socioeducativos direcionados para grupos específicos, dentre eles, os Centros de Convivência para crianças, jovens e idosos. (MDS/2004)

\section{Reordenamento dos Serviços de Convivência e Fortalecimento de Vínculos}

Algumas considerações acerca dos Serviços de Convivência e Fortalecimento de Vínculos SCFV. Trata-se de um Serviço da Proteção Social Básica do SUAS, regulamentado pela Tipificação Nacional de Serviços Sócio-assistenciais (Resolução CNAS nº 109/2009). E foi reordenado em 2013 por meio da Resolução CNAS n01/2013.

O Reordenamento do Serviço de Convivência e Fortalecimento de Vínculos (SCFV), no âmbito do Sistema Único da Assistência Social (SUAS), visa equalizar a oferta do SCFV para as faixas etárias de ( 0 a 17) anos e acima de 60 anos, unificar a lógica de financiamento e estimular a inserção do público identificado nas situações prioritárias, conforme pactuado na Comissão Inter gestores Tripartite - (CIT) e deliberado pelo Conselho Nacional de Assistência Social CNAS. (PEREIRA, 2000)

Por Reordenamento entende-se a unificação das regras para a oferta qualificada do SCFV, que visa equalizar/uniformizara oferta, unificar a lógica de co-financiamento federal, possibilitar o planejamento da oferta de acordo com a demanda local, garantir serviços continuados, potencializar a inclusão dos usuários identificados nas situações prioritárias e facilitar a execução do SCFV, otimizando os recursos humanos, materiais e financeiros.

O Serviço de Convivência e fortalecimento é ofertado de forma complementar ao trabalho social com famílias realizado por meio do Serviço de Proteção e Atendimento Integral às Famílias (PAIF) e Serviço de Proteção e Atendimento Especializado às Famílias e Indivíduos(PAEFI) O SCFV possui um caráter preventivo e proativo, pautado na defesa e afirmação de direitos e no desenvolvimento de capacidades e potencialidades dos usuários, com vistas ao alcance de alternativas emancipatória para o enfrentamento das vulnerabilidades sociais. Deve ser ofertado de modo a garantir as seguranças de acolhida, de convívio familiar e comunitário, além de estimular o desenvolvimento da autonomia dos usuários. Os usuários do (SCFV) são divididos em grupos a partir de intervalos de faixas etárias. (MÜLLER, 2002) 
Id on Line Revista Multidisciplinar e de Psicologia

Id on Line Multidisciplinary and Psycology Journal

De acordo com Yazbek (2008), o trabalho nos grupos é organizado em percursos de forma a estimular as trocas culturais e a partilha de vivências, desenvolver o sentimento de pertença e de identidade, fortalecer os vínculos familiares sempre sob a perspectiva de incentivar a socialização e a convivência familiar e comunitária.

Sendo assim o Público do Serviço de Convivência e Fortalecimento de Vínculos em sua maioria são Crianças de até 6 anos, em especial: Crianças com deficiência, com prioridade para as beneficiárias do (BPC); Crianças cujas famílias são beneficiárias de programas de transferência de renda; Crianças encaminhadas pelos serviços da Proteção Social Especial; Crianças residentes em territórios com ausência ou precariedade na oferta de serviços e oportunidades de convívio familiar e comunitário; Crianças que vivenciam situações de fragilização de vínculos. (ESTATUTO DA CRIANÇA E DO ADOLESCENTE -ECA, 1990)

Já para Crianças e adolescentes de 6 a 15 anos, em especial: Crianças e adolescentes com deficiência, com prioridade para as beneficiárias do BPC; Crianças e adolescentes cujas famílias são beneficiárias de programas de transferência de renda; Crianças e adolescentes de famílias com precário acesso à renda e a serviços públicos. Adolescentes de 15 a 17 anos, tais como Adolescentes pertencentes às famílias beneficiárias de programas de transferência de renda; Adolescentes egressos de medida socioeducativa de internação ou em cumprimento de outras medidas socioeducativas em meio aberto; Adolescentes em cumprimento ou egressos de medida de proteção do Estatuto da Criança e do Adolescente (ECA, 1990).

Adolescentes do Programa de Erradicação do Trabalho Infantil (PETI) ou adolescentes egressos ou vinculados a programas de combate à violência e ao abuso e à exploração sexual.

O Serviço de Convivência e Fortalecimento de Vínculos para Crianças e Adolescentes de 6 a 15 anos é um Serviço ofertado na Proteção Social Básica, com foco na constituição de espaço de convivência, formação para a participação e cidadania, desenvolvimento do protagonismo e da autonomia das crianças e adolescentes, a partir dos interesses, da demandas e das potencialidades dessa faixa etária. Estabelece ainda que as intervenções devam ser pautadas em experiências lúdicas, culturais e esportivas como formas de expressão, interação, aprendizagem, sociabilidade e proteção social, conforme a Tipificação Nacional de Serviços Sócio-assistenciais (RESOLUÇÃO CNAS n. ${ }^{\circ} 109 / 2009$ ).

O Serviço de Convivência e Fortalecimento de Vínculos para Idosos é um Serviço da Proteção Social Básica que tem por foco o desenvolvimento de atividades que contribuam no 
processo de envelhecimento saudável, no desenvolvimento da autonomia e de sociabilidades, no fortalecimento dos vínculos familiares e do convívio comunitário e na prevenção de situações de risco social. O SCFV, que está inserido no âmbito da proteção social básica, com vistas a garantir, em conjunto com outros serviços sócio-assistenciais, a segurança de convívio aos usuários da política de assistência social (RESOLUÇÃO CNAS n. ${ }^{\circ}$ 109/2009).

\begin{abstract}
Nessa direção, a integração entre o SCFV e o PME é uma estratégia necessária tendo em vista que os mesmos usuários são atendidos pelas duas políticas sem função de sua capilaridade no território e, embora tenham objetivos diferentes, em muitos momentos, recorrem a estratégias próximas. Essa articulação fortalece o diálogo entre as políticas de educação e assistência social, em todos os âmbitos de atuação, por meio do desenvolvimento de uma agenda articulada nos municípios onde as duas ações sejam desenvolvidas. As atividades de convivência e fortalecimento de vínculos têm como principal público-alvo as crianças e adolescentes de 7 a 14 anos, já os serviços de acolhimento institucional são mais voltados aos idosos $(65,5 \%)$ e os de serviço especializado para pessoas em situação de rua para aquelas entre 18 e 59 anos $(76,2 \%)$.

(CAMPOS, 2005, p. 229)
\end{abstract}

Por essa razão, ressalta-se a necessidade de envidar esforços no âmbito da gestão das respectivas políticas quanto à articulação entre o Serviço e o Programa, visando promover intervenções que amparem, apoiem, auxiliem e resguardem os sujeitos e suas famílias, por meio de ações conjuntas de caráter projetivo e preventivo para a defesa e a promoção de seus direitos. O SCFV também é estruturado em percursos.

Todo o processo de planejamento das atividades, nos respectivos percursos, deve considerar as cognições, emoções, interesses, vulnerabilidades e avaliações dos participantes, procurando associar a diversidade de interesses e necessidades individuais às características gerais do grupo. Paralelamente à participação dos usuários no grupo de convivência, também podem participar de variadas atividades do SCFV que o município tenha disponibilidade de ofertar, tais como: oficinas de capoeira; dança regional; teatro; grafite, dentre outras. As oficinas, bem como as palestras e confraternizações eventuais, por si só não constituem o SCFV, mas são estratégias para promover a convivência (YAZBEK, 2005).

A escolha das oficinas a serem ofertadas como atividades do SCFV não é aleatória.

Estas devem dialogar com os objetivos do SCFV e com as vivências e interesses dos usuários. O público prioritário para o atendimento no SCFV, de acordo com a Resolução CNAS nº 1/2013 são crianças, adolescentes e idosos nas seguintes situações: de isolamento; de acolhimento; em trabalho infantil; com vivência de violência e negligência; fora da escola ou com defasagem 
Id on Line Revista Multidisciplinar e de Psicologia

Id on Line Multidisciplinary and Psycology Journal

escolar superior a dois anos; em cumprimento de medida socioeducativa em meio aberto; egressos de medidas socioeducativas; em situação de abuso e/ou exploração sexual; com a Tipificação Nacional dos Serviços Sócio-assistenciais foi aprovada pela Resolução do Conselho Nacional de Assistência Social (CNAS) nº 109, de 11 de novembro de 2009.

Esse documento descreve os serviços de proteção social básica e de proteção social especial do Sistema Único de Assistência Social (SUAS), apresentando os seus objetivos, o impacto social que devem promover, os usuários a que se destinam, o local onde são ofertados, entre outras informações, medidas de proteção do Estatuto da Criança e do Adolescente (ECA); em situação de rua; e com vulnerabilidade que diz respeito às pessoas com deficiência. No entanto, cabe ressaltar que, no caso específico da integração do SCFV e o PME, as ações são direcionadas para o público de 0 a 17 anos (IAMAMOTO E CARVALHO 2005).

A equipe de referência para a prestação do SCFV é composta por um técnico de nível superior e por orientadores ou educadores sociais, com formação escolar mínima de nível médio. O técnico de referência tem, entre outras, a atribuição de planejar e organizar o SCFV junto com o(s) orientador(es) social(is); acompanhar os usuários; realizar reuniões periódicas entre a equipe do SCFV e a equipe do PAIF; realizar reuniões com as famílias dos usuários, etc. Já os orientadores ou educadores sociais são os responsáveis diretos pela condução dos grupos de convivência e suas atribuições específicas estão elencadas na Resolução CNAS nº 09/2014, a saber: desenvolver atividades socioeducativas e de convivência e socialização visando à atenção, defesa e garantia de direitos e proteção aos indivíduos e famílias em situações de vulnerabilidade e/ou risco social e pessoal; acompanhar, orientar e monitorar os usuários na execução das atividades; apoiar na organização de eventos artísticos, lúdicos e culturais nas unidades e/ou na comunidade; apoiar na elaboração de registros das atividades desenvolvidas, subsidiando a equipe com insumos para a relação com os órgãos de defesa de direitos e para o preenchimento do Plano de Acompanhamento Individual e/ou familiar do PAIF; participar das reuniões de equipe para o planejamento das atividades, avaliação de processos, fluxos de trabalho e resultado; desenvolver atividades que contribuam com a prevenção de rompimentos de vínculos familiares e comunitários; apoiar na identificação e acompanhamento das famílias em descumprimento de condicionalidades do PBF; acompanhar o ingresso, frequência e o desempenho dos usuários por meio de registros periódicos. O SCFV é contínuo e ininterrupto, devendo estar disponível à população independentemente dos períodos de recesso e férias 
escolares. Cada unidade executora do serviço tem a responsabilidade de organizar uma grade horária para atender aos grupos de convivência e às respectivas faixas etárias, conforme a demanda existente no território. (SILVA, 2009)

Os usuários podem chegar ao CRAS por demanda espontânea, busca ativa, encaminhamento da rede soco assistencial ou encaminhamento das demais políticas públicas e de órgãos do Sistema de Garantia de Direitos. O SCFV pode ser ofertado no próprio CRAS, desde que haja espaço físico compatível; em outras unidades públicas -como nos centros de convivência - e em entidades soco assistenciais cadastradas no Conselho Municipal de Assistência Social.

A oferta desse Serviço para crianças e adolescentes fundamenta-se em três eixos orientadores:

I - Convivência social, a partir do qual as ações e atividades devem estimular o convívio social e familiar, os aspectos relacionados ao sentimento de pertença, à formação da identidade, à construção de processos de sociabilidade, aos laços sociais, às relações de cidadania; II - Direito de ser, que promove experiências que potencializem a vivência dos ciclos etários da infância e da adolescência em toda a sua pluralidade; I,II - Participação, que tem como foco estimular, mediante a oferta de atividades planejadas, a participação dos usuários nas diversas esferas da vida pública, a começar pelo Serviço de Convivência e Fortalecimento de Vínculos, passando pela família, comunidade, escola, espaços públicos, tendo em mente o seu desenvolvimento como sujeito de direitos e cidadão (TEIXEIRA, 1995, p. 20).

São Paulo é o estado que mais concentra instituições de assistência social $(28,7 \%)$, seguido de Minas Gerais (17,1\%), Paraná (10,8\%), do Rio Grande do Sul (8,5\%), de Santa Catarina (6,6\%), do Rio de Janeiro $(5,1 \%)$ e da Bahia (3,7\%). Acre, Amapá e Roraima são os locais com menos entidades.

O trabalho socioeducativo com famílias ou grupos de famílias, bem como os procedimentos individuais de acolhimento, escuta qualificada, encaminhamentos e acompanhamentos devem buscar a inserção desses sujeitos no circuito do território e da rede de segurança social e articular o individual e o familiar no contexto social, levando esses sujeitos a ultrapassar o imediatismo de suas concepções, mas tendo como princípio que subjetividades transformadas só provocam mudanças com ações coletivas, com acesso a serviços, benefícios, ou seja, com condições objetivas. Todavia, só o acesso a serviços e benefícios como dádiva, benesse, caridade não provoca mudanças subjetivas políticas, autonomia e cidadania, mas sim subalternidade e tutela. 
Id on Line Revista Multidisciplinar e de Psicologia

Id on Line Multidisciplinary and Psycology Journal

\section{Métodos e Procedimentos}

A abordagem metodológica foi do tipo exploratória documental e bibliográfica pois "[...] preocupou-se em analisar e interpretar aspectos mais relevantes descrevendo a complexidade do comportamento humano" (LAKATOS; MARCONI, 2003, p. 77). Participaram deste estudo 25 sujeitos, sendo: 01 assistente social, 01 educador social, 01 oficineiro, 01 coordenador, 01psicólogo, 10 jovens de 14 a 17 anos e 10 famílias que participam dos programas do CRAS, em estudo.

Durante as entrevistas preocupou-se com a análise e interpretação dos fatos e acontecimentos do dia a dia destes atores, o que nos permitiu conhecer mais, acerca da vulnerabilidades dessas famílias. Quanto aos processos de execução dos serviços ofertados nas unidades dos CRAS, foi desenvolvido a seguinte trajetória: leitura de diversas fontes informativas que norteiam e regulamentam o trabalho da política de assistência Social nos (CRAS), manuais e instrumentais dos (CRAS), análise de material de referência e orientação produzido no âmbito do MDS, Tipificação do Reordenamento dos Serviços e Fortalecimento de Vínculos, entrevistas com assistentes sociais E visitas técnicas a unidade (CRAS II) do Alto da Boa Vista.

O objetivo principal deste estudo foi analisar como se estabelecem as relações dos usuários dos serviços de convivência e fortalecimento de vínculos (SCFV) junto às suas famílias, identificando na prática as barreiras impedem o alcance dos mesmos. Os objetivos específicos foram: 1) Identificar os obstáculos e dificuldades apresentadas por essas famílias na expressão do seu protagonismo dentro e fora dos espaços do Centro de Referência e Assistência Social e, 2) Contribuir para a sociedade mediante reflexão dos textos abordados, na busca de melhores alternativas e estratégias, que melhor se apliquem à realidade de cada família usuária dos serviços do Centro de Referência e Assistência Social.

\section{Procedimentos}

Para chegarmos aos objetivos que levaram a realização deste trabalho, foram realizados duas fases, a primeira, bibliográfica e documental, apresentada nos capítulos anteriores contendo reflexões históricas e teóricas. Essa revisão da literatura teve seu 
embasamento teórico em livros periódicos, manuais de orientação do MDS, leis e artigos científicos, entre outras fontes de pesquisa.

Segundo OLIVEIRA (2007), a revisão da literatura tem por finalidade o contato direto com obras, artigos e documentos que farão com que tenhamos uma maior aproximação do tema pesquisado. A segunda fase de características de campo, foi aplicada no CRAS, e em visitas domiciliares a algumas famílias do PAIF. O método utilizado para a obtenção das respostas esperadas pela pesquisa de campo foi um questionário com questões abertas para que pudéssemos deixar os entrevistados à vontade a partir do perfil das famílias em situação de vulnerabilidade social inscritas no Programa de Atenção Integral a Família (PAINF).

Quanto a sua resposta e análise das perguntas apresentadas, como nos descreve GIL (1999 p. 121): "Nas questões abertas, apresenta-se a pergunta e deixa-se um espaço em branco para que a pessoa escreva sua resposta sem qualquer restrição".

\begin{abstract}
A pesquisa foi realizada de forma qualitativa, que pode ser entendido sendo um processo de reflexão e análise da realidade através da utilização de métodos e técnicas para compreensão detalhada do objeto de estudo em seu contexto histórico e/ou segundo sua estruturação (OLIVEIRA, 2001, p.37)
\end{abstract}

A escolha por aplicação do questionário como nos exemplifica GIL:

(...) b) implica menos gastos com pessoal, posto que o questionário não exige o treinamento de pesquisadores; c) garante o anonimato das respostas; d) permite que as pessoas respondam no momento em que julgarem mais conveniente; (e principalmente) e) não expõe os pesquisados à influência das opiniões e do aspecto pessoal do entrevistador. (GIL, 1999, p. 122)

A análise da pesquisa não se limita as respostas obtidas no decorrer do questionário, busca-se também a utilização da observação participante, analisando a prática profissional como um todo, observando as vantagens e desafios que o espaço institucional proporciona aos assistentes sociais, a equipe técnica e aos usuários. Os assistentes sociais autorizaram o uso de suas respostas para o presente projeto, deixando claro que não temos por finalidade aqui, expor nomes ou qualquer forma de identificação, profissional. Utilizaremos os dados coletados como forma de amostra deste universo profissional e para o debate.

Nas visitas, foram realizadas entrevistas com as equipes técnicas de cada CRAS, onde foram efetuados vários deslocamentos a estas unidades ampliando assim as observações e coleta 
Id on Line Revista Multidisciplinar e de Psicologia

Id on Line Multidisciplinary and Psycology Journal

de dados, os quais serão abordados a seguir: Uma pesquisa é sempre, de alguma forma, um relato de longa viagem empreendida por um sujeito cujo olhar vasculha lugares muitas vezes já visitados. Nada de absolutamente original, portanto, mas um modo diferente de olhar e pensar determinada realidade a partir de uma experiência e de uma apropriação do conhecimento que são, aí sim, bastante pessoais.

Essas situações de contato exigem atenção redobrada por parte do pesquisador, pois ele corre o risco de ver a entrevista escapar-lhe completamente das mãos e perder-se dos objetivos da pesquisa, restringindo-se a divagações ou, mesmo, resvalando para uma espécie de troca de experiências mútuas, que compromete bastante a qualidade do trabalho.

Sendo assim a entrevista foi realizada de forma conjunta entre assistentes sociais, psicólogo, coordenadores e educadores sociais com o objetivo de contextualizar as informações, uma vez que todos eles trabalham com o mesmo público.

\section{Resultados e Discussão}

A parte de campo dessa pesquisa aconteceu no Centro de Referência e Assistência Social do Alto da Boa Vista CRAS II, no município de Araripina - PE, no primeiro semestre de 2014, no município de Araripina PE, no Centro de Referência e Assistência Social (CRASII) Alto da Boa Vista.

Araripina localiza-se no estado de Pernambuco a 600 km da capital Recife. O município se estende por $1892,6 \mathrm{~km}^{2}$ e conta com uma população estimada atualmente de 82.800 habitantes no último censo 2015. A densidade demográfica é de 40,9 habitantes por $\mathrm{km}^{2}$ no território do município. Faz fronteira com os municípios de Trindade, Marcolândia e Simões.

Conta há três Centros de Referencias e Assistência Social, sendo: 01 localizado na comunidade do Alto da Boa Vista, CRAS II, 01 localizado no distrito de Morais o CRAS III, e mais 01 localizado na comunidade do Cavalete 01, o CRAS I e mais 01 unidade de Serviço de Convivência e Fortalecimento de Vínculos, localizado na divisa do Estado do Piauí com Pernambuco, comunidade de Vila Serrânea.

O CRAS da Comunidade do Alto da Boa Vista é composto pela seguinte equipe técnica: 01 coordenador, 02 assistentes sociais, 01 psicólogo, 02 educadores sociais, 02 oficineiros, 01 equipe de atendimento específico aos usuários do Programa Bolsa Família, 01 vigia, 01 
Id on Line Revista Multidisciplinar e de Psicologia

Id on Line Multidisciplinary and Psycology Journal

motorista, 01 secretaria, 02 atendentes serviços gerais, 01 cozinheira. Essa composição varia de um CRAS para outro conforme o número de habitantes. Os serviços ofertados comuns a todos os CRAS citados são: acolhida, atendimento escuta, visitas domiciliares, encaminhamentos, visita de campo, ações em parceria com outras secretarias afins, campanhas educativas, palestras, fóruns entre outros.

A finalidade deste estudo foi proporcionar o entendimento aos participantes dos Programas do CRAS sobre a proteção das capacidades de transformação familiar, reajuste e adaptação que resultam em novas formas de relação inter e extra familiar, que se dá pelo fortalecimento e empoderamento da família.

\section{Entrevistas com os Técnicos do CRAS}

Os serviços de convivência e fortalecimento de vínculos podem ser organizados por ciclo de vida ou ser Inter geracionais, tendo sempre a centralidade na família. $\mathrm{O}$ fato destes serviços se destinarem a pessoas em determinadas faixas etárias, não caracteriza fragmentação de ações. Este trabalho volta-se a abordar as características de vulnerabilidade, de potencialidades e de desenvolvimento, relativas às faixas etárias e aos contextos sociofamiliares, como suporte ao trabalho com famílias realizado pelo PAIF. Parte-se da concepção de que os ciclos de vida familiar têm estreita ligação com os ciclos de vida de desenvolvimento dos sujeitos que as compõem. São serviços com objetivos alvos de trabalho bem caracterizados, específicos, em estreita colaboração e integração com as atividades do PAIF, pressupondo um trabalho continuado.

De acordo com a entrevista feita aos técnicos dos CRAS sobre como funciona os programas junto com as famílias, as respostas foram sumarizadas da seguinte forma:

Tabela 1 - Resultados das Entrevistas com os Técnicos do CRAS. Araripina-PE, 2014.

\section{Questionamentos e Respostas dos sujeitos}

1 - Quantos usuários do serviço de convivência e fortalecimento de vínculos são atendidos nesta unidade? R: São 300, sendo 140 na sede e 160 na zona rural;

2 - Quais são os serviços ofertados dentro do CRAS? R: Além dos (SCFV), serviços do (PAIF) Programa de Atenção Integral a Família, cadastros das famílias aos programas, atendimento escuta, encaminhamentos, visitas e articulação com outras políticas públicas de direito; 
Id on Line Revista Multidisciplinar e de Psicologia

Id on Line Multidisciplinary and Psycology Journal

3 - Como se dá o processo de inclusão desses usuários nos grupos? R: Primeiro é feito um atendimento de ambas as partes, mãe e filho individualmente num processo de escuta e observações, em seguida o mesmo é inserido em um grupo de acordo com sua faixa etária;

4 - Quais são as atividades desenvolvidas com os usuários dos serviços de convivência e fortalecimento de vínculos dentro e fora do espaço do CRAS? R: São desenvolvidos ' $n$ ' projetos dos quais: artes com grafitagem, pintura em tecidos, material recicláveis, música com violão, coral, oficinas de artesanatos, brincadeiras lúdicas, dinâmicas, cultivo de hortas, atividades esportivas, confecção de pequenas amostras com a história de vida pessoal de cada um;

5 - Qual a participação dos pais junto aos filhos nas atividades realizadas nos grupos de convivência e fortalecimento de vínculos? R: Por meio dos grupos Inter geracionais, na realização de palestras, eventos, oficinas de geração de renda brincadeiras lúdicas entre outros...;

6 - De que maneira esse fortalecimento de vínculos se estabelece na relação mãe e filho? R: A partir do compromisso assumido pelos pais junto a instituição;

7 - Quais são as barreiras que se contrapõem ao alcance dos objetivos do SCFV, junto as famílias? $R$ : Boa parte das famílias contempladas com os programas desconhecem os objetivos dos serviços ofertados algumas por apresentarem pouco entendimento, outras por não se fazerem presentes nas palestras e eventos, por estarem em outros espaços buscando meios para sua própria sobrevivência, maridos alcoólatras, filhos com outros tipos de distúrbios psicológicos e outras dependências.

8 - Quais são os entraves e limitações que se interpõem na execução dos serviços junto a equipe do CRAS? R: Equipe técnica insuficiente condicionada a baixos salários, recursos financeiros e materiais insuficientes para a demanda, falta de articulação entre outras secretarias adjuntas de políticas de direito, famílias apresentando problemas e situações diversas com demandas de outras políticas que terminam buscando atendimento na secretaria de assistência.

Fonte: Pesquisa.

Constatou-se que os objetivos dos serviços de convivência e fortalecimento de vínculos, na prática não se alcançam de fato como são propostos pois são muitos os problemas que interferem ao alcance desses objetivos desde a falta de conhecimento e interesse dos usuários quanto ao empoderamento da própria política de direito.

Quanto a execução dos programas nas três esferas de governo municipal, estadual e federal, sobretudo no tocante ao papel dos conselhos, que por ser composto por $50 \%$ da sociedade civil e 50\% governo nem sempre exerce o seu papel que é de caráter voluntário e boa parte são ligados aos órgãos do governo em sistema de vínculo empregatício por tempo determinado.

Segundo declaração dos técnicos do CRAS, que apesar dos esforços percebe-se ainda uma enorme desarticulação na execução dos serviços entre outras secretarias e instituições afins, em que todas trabalham praticamente com os mesmos tipos de usuários, mas infelizmente de forma desarticulada, ou seja não há uma comunicação de referência e contra referência dos 
Id on Line Revista Multidisciplinar e de Psicologia

Id on Line Multidisciplinary and Psycology Journal

problemas em foco e possíveis soluções no atendimento desses usuários, acontece mas de forma tímida.

Em conversas informais com a assistente social, há de se observar também a falta de recursos de suporte técnico com um grande número de rotatividade, recursos financeiros, estrutural nas unidades dos CRAS, impossibilitando a oferta de um serviço de qualidade. Por outro lado há um outro agravante bem complexo, cada família assistida pelo (CRAS), apresenta um leque de problemas que demanda uma ação urgente por parte outras secretarias e instituições em que na maioria das vezes, não apresenta muita vontade e poder de resolução, dos muitos problemas que atinge a classe mais vulnerável, dentre esses: maridos alcoólatras, filhos usuários de drogas, prostituição em adolescentes, desemprego, violência doméstica, falta de alimentação entre outros.

Com isso percebe-se que a problemática que atinge essas famílias vai muito mais além do que um simples atendimento no CRAS, um simples cadastramento no bolsa família, fato esse que de um total de 1000 famílias cadastradas no programa apenas $10 \%$ alcancem a sua autonomia. Diante dessa realidade percebe-se que os serviços de convivência e fortalecimento (SCFV), estão longe de atingir os seus objetivos podendo ainda até acontecer, mas de forma lenta e precária retardando assim o alcance da autonomia e protagonismo dessas famílias e seus usuários.

$\mathrm{O}$ trabalho de pesquisa junto aos funcionários (CRAS) possibilitou o conhecimento dos diversos problemas que afligem as famílias cadastradas, ampliando o nosso conhecimento de situações que caminham na contramão do alcance dos objetivos do dos SCFV, uma vez que essas situações interferem de forma direta com a participação dos mesmos nos serviços e programas. Dentre os quais temos: famílias com pais alcoólatras, filhos usuários, pais desempregados vivendo unicamente com o rendimento do Programa Bolsa Família, composição familiar formada numa média de sete a dez pessoas morando num mesmo espaço de três a quatro cômodos, crianças jovens adolescentes expostos a todo tipo de vulnerabilidade social em que não se sentem acolhidos na própria família. Moradias sem saneamento básico entre outros.

Uma vez chegando até o CRAS, os usuários são acolhidos pelos técnicos os quais e requerem orientações gerais. Da mesma forma, referenciam a importância das ações na 
Id on Line Revista Multidisciplinar e de Psicologia

Id on Line Multidisciplinary and Psycology Journal

mudança de estilos de vida, bem como o melhor entendimento e conhecimento acerca dos serviços oferecidos pelos órgãos públicos.

Diante desses relatos, pode-se inferir que as ações sócio educativas do (PAIF), são capazes de sensibilizar os usuários em relação aos temas abordados, contribuindo para a promoção da saúde e cidadania. Na execução das ações são priorizadas as rodas de conversas e oficinas dialogadas em detrimento às palestras convencionais.

A partir da demanda apresentada pelo grupo, os mesmos são direcionados a outros equipamentos sociais na perspectiva do planejamento coletivo, as ações são sugeridas pelos participantes, cujos temas de interesse são incorporados ao planejamento das atividades.

$\mathrm{Na}$ execução das atividades, são utilizados projetor multimídia, computador, microfone e caixas de som. Todos os encontros são registrados por meio de fotografia e lista de presença. Relatos cotidianos feitos pelos participantes atestam que a participação nas ações socioeducativas contribuiu significativamente para a melhoria de seus comportamentos e atitudes dos mesmos frente aos seus familiares e a sociedade.

De acordo com conversas informais com os participantes do programa, relatam que antes de participar das ações não tinham conhecimento acercados programas e projetos do município, bem como de seus direitos. Verifica-se que a prática profissional do Assistente Social pressupõe a articulação com as demais secretarias municipais, organizações sociais e a comunidade.

\footnotetext{
As ações visam o desenvolvimento da comunidade com a participação dos sujeitos em todo o processo de intervenção, de forma participativa e integrada. Além disso, o profissional utiliza-se de um conjunto de técnicas, conhecimentos, estudos, informações, habilidades que, embora nem sempre perceptíveis aos sujeitos, vão se modernizando e ampliando no processo (GUERRA, 1995, p. 296).
}

Sabe também que deve adotar uma postura investigativa para vislumbrar novas possibilidades de trabalho diante das demandas emergentes do atual contexto em que vivemos. O Assistente Social luta pela ampliação da cidadania, que visa a efetivação dos direitos civis, políticos, sociais de todos os cidadãos (IAMAMOTO, 2008).

Contudo, é necessário ir além e ampliar o olhar sobre os direitos no Programa. Para tanto, a pesquisa social deverá ser uma constante, o que possibilitará conhecer, problematizar e aprofundar os conhecimentos sobre a realidade alvo da intervenção, que por sua vez apresenta questões que desafiam os técnicos da política de assistência. O atendimento social às famílias 
Id on Line Revista Multidisciplinar e de Psicologia

Id on Line Multidisciplinary and Psycology Journal

compreende duas práticas de competência do Assistente Social - a orientação e o acompanhamento social - e possui um forte viés socioeducativo, o qual informa e influência na tomada de consciência da realidade vivida pela família, bem como suas decisões.

A resposta às demandas coletivas perpassa a compreensão das demandas singulares, num movimento crítico e historicamente situado. Nessa perspectiva, o atendimento integral às famílias pressupõe o respeito aos vínculos sociais, familiares e comunitários, e a mobilização e articulação da rede de serviços públicos para atender as demandas postas pelas famílias, conectadas aos níveis de proteção social do SUAS.

Neste contexto, verifica-se que a ação ou intervenção profissional dos assistentes sociais nas poligonais não é um conjunto de passos preestabelecidos (FALEIROS, 2005, p. 65), mas sim, uma ação dinâmica que exige o diálogo, uma compreensão dos limites e possibilidades institucionais e uma capacidade teórica, analítica e de proposição que envolve a participação do sujeito e dos outros servidores que trabalham nas demais secretarias. Portanto, as ações visam o desenvolvimento da comunidade com a participação dos sujeitos e de outros profissionais em todo o processo de intervenção (pré-urbanização, urbanização e pósurbanização).

Como diz Souza (2008, p. 81), “a participação é o próprio processo de criação do homem ao pensar e agir sobre os desafios da natureza e sobre os desafios sociais, nos quais ele próprio está situado". Como tal, é um processo dinâmico e contraditório.

\section{Entrevistas com os jovens participantes dos Programas do CRAS}

Diversas características da condição de vida em que as pessoas se encontram podem ser indicadores das vulnerabilidades ou dos agravamentos que atingem as famílias e as crianças de até 06 anos e que podem afetar os vínculos. Como fatores de agravamento da vulnerabilidade e do risco social, estudos apontam para características individuais, familiares, sociais e do território, tais como: a pobreza, a violência doméstica e sexual, a negligência, o trabalho infantil, as deficiências e trajetórias de vidas nas ruas, entre outras, associadas às dificuldades ambientais do território.

É reconhecida a complexa interação entre fatores biológicos que podem desencadear vulnerabilidades, o ambiente vivenciado e a presença/ausência de suporte social, sendo este o 
Id on Line Revista Multidisciplinar e de Psicologia

Id on Line Multidisciplinary and Psycology Journal

ponto de partida para a identificação, no território, da demanda pelo Serviço apresentado neste documento.

Por meio dessa oferta, integrante do Serviço de Convivência e Fortalecimento de Vínculos, os adolescentes participam de oficinas de esportes, música, fotografia, meio ambiente, cinema, além de rodas de conversas sobre as temáticas que permeiam a vida de um jovem. Além disso, os participantes e pais recebem informações e orientações para inclusão desses adolescentes no trabalho protegido, caso esse seja interesse do jovem e da família.

Diante disso perguntou-se aos jovens participantes dos programas do CRAS, o que fez eles procurarem os serviços de proteção social.

Gráfico 1 - Opinião dos jovens sobre a procura dos serviços do CRAS.

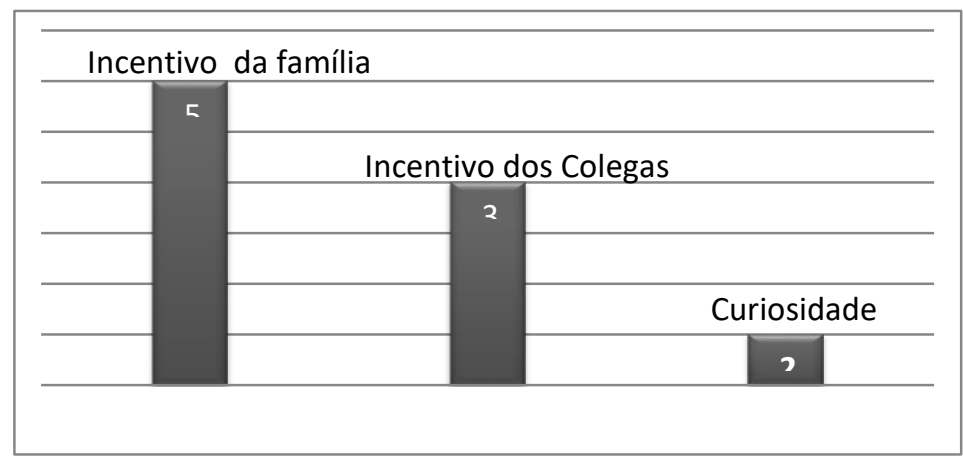

Cinco dos participantes responderam por incentivo da família, três por incentivo dos colegas que participam dos programas do CRAS e dois apenas por curiosidade.

A busca ativa, papel da equipe de referência do CRAS, é um ponto fundamental para o trabalho em rede e para o serviço que apresentamos neste documento técnico. Consiste no trabalho de procura intencional, reconhecimento e identificação das situações de risco e vulnerabilidade social no território, viabilizando também o conhecimento da sua realidade social (Caderno CRAS, 2009).

A ação da Proteção Social Básica através do CRAS, do PAIF e dos serviços específicos junto às ocorrências de vulnerabilidade é uma via de ação preventiva de situações de risco nos seus territórios, também incitando à participação social.

Trabalhar nesse sentido é um dos objetivos principais das ações de Proteção Social Básica, o que ocorre através do referenciamento da rede sócio assistencial ao CRAS, sua 
Id on Line Revista Multidisciplinar e de Psicologia

Id on Line Multidisciplinary and Psycology Journal

articulação ao PAIF e aos demais Serviços de políticas públicas voltadas aos segmentos populacionais em situação de vulnerabilidade.

Para compreender a importância do trabalho com a faixa etária dos jovens e suas famílias que participarão do presente Serviço, deve-se atentar tanto para as vulnerabilidades quanto para as características das crianças e das famílias, das potencialidades e de desenvolvimento humano.

Conforme a pergunta de número 2 sobre gostar dos trabalhos dos profissionais que atuam nesse CRAS. A maioria (sete) respondeu que gosta do trabalho dos técnicos do CRAS, conforme mostra o Gráfico 2 abaixo.

Gráfico 2 - Opinião dos jovens sobre a gostar do trabalho dos profissionais do CRAS

\begin{tabular}{|c|c|c|}
\hline Sim & & \\
\hline \multirow[t]{6}{*}{7} & & \\
\hline & & \\
\hline & & \\
\hline & Vão & \\
\hline & ? & Às Vezes \\
\hline & & 1 \\
\hline
\end{tabular}

Estas opiniões dos entrevistados nos ajuda a entender o trabalho profissional da equipe interdisciplinar no CRAS e a direção do trabalho social com famílias, dependentes não apenas de seus referenciais teóricos, concepções e visões de mundo, mas também da direção dada pelo Ministério do Desenvolvimento Social, gestor, coordenadores, dentre outros, mesmo que isso não exima os profissionais de suas responsabilidades em relação ao que é posto em prática, considerando sua relativa autonomia como trabalho especializado.

Em relação ao trabalho profissional nos CRAS, compreende uma dimensão individual de atendimento, orientação e encaminhamentos para a rede, e uma dimensão coletiva, com os grupos de sujeitos por segmento ou faixa etária e grupos de famílias, nos quais se delimitam também os tipos de procedimentos a serem adotados, as técnicas ou instrumentos possíveis de serem utilizados. 
Id on Line Revista Multidisciplinar e de Psicologia

Id on Line Multidisciplinary and Psycology Journal

Em conversas informas nos CRAS os técnicos destacam tanto os procedimentos e ações profissionais realizadas como as técnicas e os objetivos que visam a essas ações e serviços. As ações de cunho individual incluem desde o acolhimento que também repassa informações, escuta qualificada para detectar vulnerabilidades e riscos, bem como para levantar demandas, e o encaminhamento para os serviços da rede sócio-assistencial e de outras políticas sociais. As técnicas mais utilizadas são as entrevistas e as visitas domiciliares.

Há um consenso nacional e internacional de que o caminho mais eficaz para a resolução das violações de direitos das crianças é o desenvolvimento de políticas públicas básicas, preventivas e que evitem situações de risco, considerando as características próprias da criança e para a organização do grupo familiar e social dos quais a família participa.

As ações devem incentivar e capacitar para a participação e o controle social. Enquanto situações de vulnerabilidade e riscos que podem atingir diretamente as crianças, destacamos a ocorrência de deficiência, o trabalho infantil, violência, crianças reconduzidas ao convívio familiar após medida protetiva de acolhimento entre outras situações encaminhadas pela Proteção Social Especial. (PASTORINI, 2010)

Cabe às equipes de proteção social básica, a identificação de situações de vulnerabilidade social e familiar às quais as famílias e crianças possam estar expostas, como, por exemplo, a fragilização de vínculos ou mesmo o risco de seu rompimento, para que possa intervir de maneira preventiva, atendendo a sua função primeira de trabalho de prevenção de situações de risco, desenvolvendo potencialidades, aquisições e o fortalecimento de vínculos sociais e familiares (NOB-SUAS) e das redes que os compõem

Para tanto, é preciso desenvolver ações ou projetos dentro do programa da forma que se torne atraente para o público alvo que se pretende atingir. Nesse contexto, a equipe do CRAS fez algumas sugestões ao órgão gestor para oferecer maior qualidade deste serviço para as crianças e os adolescentes participantes: instalação de um laboratório de informática no CRAS com o intuito de facilitar o acesso à tecnologia da informação; parceria sólida com a Fundação Municipal do Desporto no sentido de oferecer diversas modalidades de esporte 13 (futebol, vôlei, judô, basquete e outros); parceria sistemática com a Fundação Cultural para a garantia do acesso deste público à cultura; construção da área de lazer na comunidade em que está situado o CRAS; aquisição de equipamentos eletrônicos para facilitar a comunicação e o acesso à informação (notebook, Datashow, máquina digital) 
Diante da pergunta de número 3 perguntou-se aos jovens entrevistados sobre quais atividades ou oficinas oferecidas nos CRAS que eles mais gostam. Dois jovens escolheram atividades relacionadas a jogos, dois jovens optaram por pinturas em tela, quatro capoeira, um aulas de violão e um artesanatos.

Gráfico 3 - Atividades que os jovens gostam dentro dos programas do CRAS

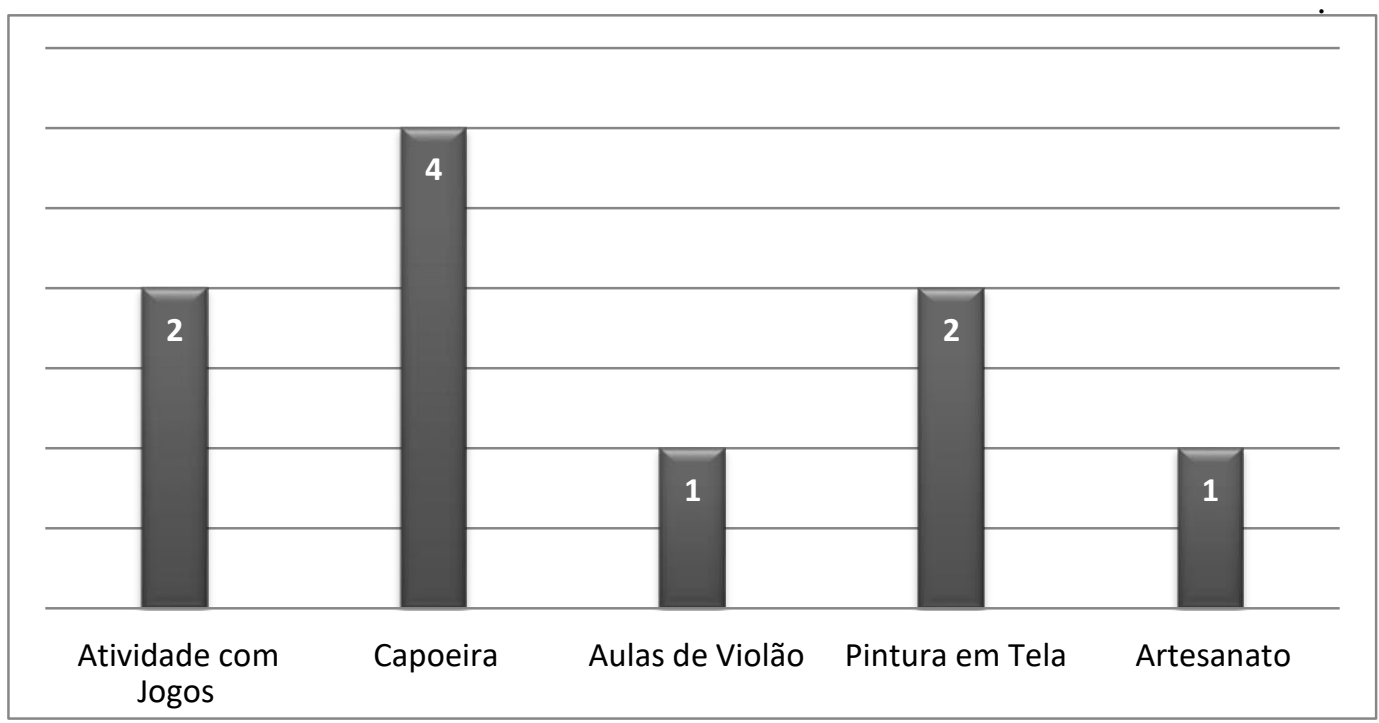

Os jogos são atividades vivas e dinâmicas, criados e construídos pelo ser humano e que, com o passar dos anos, foram recriados com diferentes estruturas, sofrendo modificações de suas regras, materiais, símbolos e maneiras de jogar. Contudo, não se perdeu o valor que os jogos agregam ao desenvolvimento individual, social e afetivo do ser humano. Torna-se evidente a grande importância em orientar corretamente os jogos infantis e juvenis. É por meio desses momentos lúdicos que as crianças e os adolescentes observam, exploram, elaboram hipóteses, compreendem o mundo em que vivem e contribuem para resolver situações de conflito no seu cotidiano.

As atividades que acontecem nas oficinas têm como objetivo primeiro formar um ambiente socializador que propicie o desenvolvimento da identidade da criança, do adolescente e do próprio grupo, por meio de aprendizagens diversificadas, realizadas em situações de interação e descontração.

A música é uma arte. Compor, interpretar, improvisar, ouvir, entrar em contato com instrumentos - o trabalho com música deve possibilitar tudo isso. Mas, acima de tudo, tem de 
Id on Line Revista Multidisciplinar e de Psicologia

Id on Line Multidisciplinary and Psycology Journal

ser significativo para o desenvolvimento das pessoas em sua capacidade de apreciar e produzir música. A voz, o gesto e a música são formas de expressão através das quais é possível estabelecer comunicação entre os seres humanos. A voz é o primeiro instrumento musical que as pessoas podem utilizar, e a canção constitui a maneira mais fácil e espontânea de se fazer música. Por meio das canções, crianças, adolescentes e adultos podem ter contato com a sua cultura e, ao mesmo tempo, conhecer a existência de outras culturas e línguas mais distantes.

Para que seja definido como local de funcionamento do Serviço, o espaço deverá localizar-se no CRAS ou no seu território de abrangência, ou seja, perto do local de moradia das famílias. Deverá contar, no mínimo, com instalações sanitárias compatíveis com o número de pessoas atendidas ao mesmo tempo, acessibilidade para todos, sala propícia ao trabalho com grupos de mais de 25 pessoas - no CRAS, onde ocorrerão as atividades com famílias e espaço adequado e acolhedor para o trabalho com crianças, que pode ou não ser um espaço do CRAS, sendo uma sala com brinquedos, arejada, limpa, colorida e segura para o trabalho do orientador de atividades lúdicas, com materiais pedagógicos, culturais e esportivos que viabilizem o trabalho com crianças e suas famílias e estimulem a interação e as brincadeiras. Note-se que parte das atividades são obrigatoriamente realizadas no CRAS, tais como: o acompanhamento e as atividades com as famílias. (BRASIL, 2006)

O Gráfico de número 4 relata sobre a participação dos jovens em atividades de geração de renda dentro do CRAS. Seis dos jovens do CRAS participam de atividades que geram renda, como por exemplo: pinturas em pano, sabonetes artesanais, arranjos de flores, etc.

Gráfico 4 - Interesse dos jovens sobre a participação em atividades que geram RENDA.

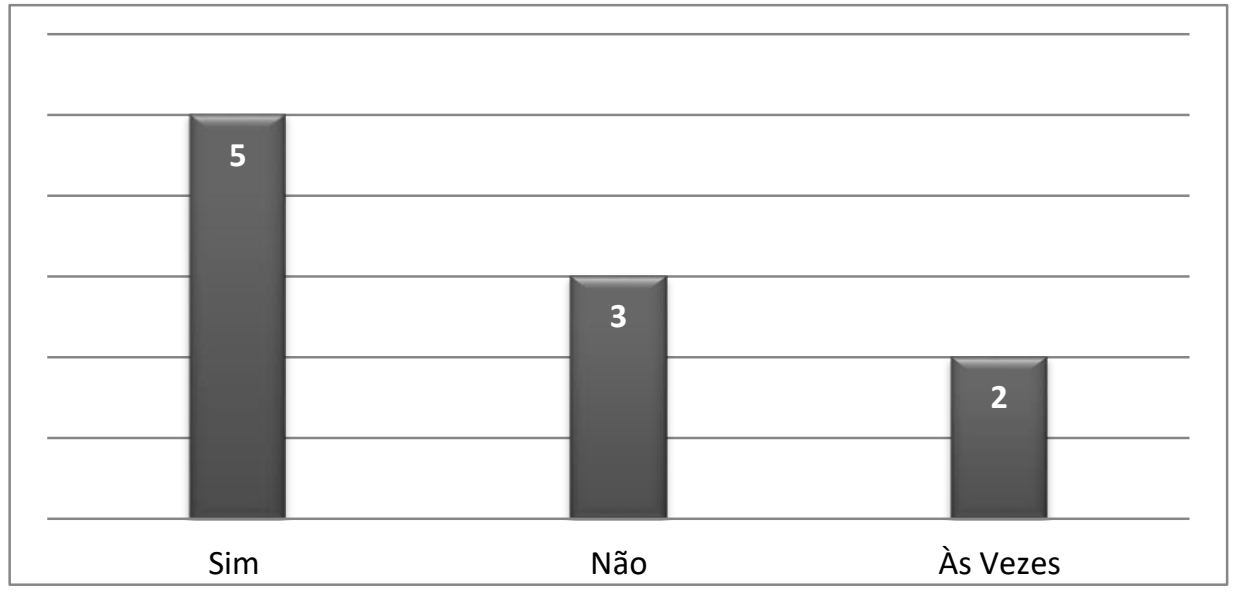


O trabalho socioeducativo é cada vez mais necessário, pois, como destaca Mioto (2004), a cidadania não se restringe ao acesso a benefício monetário, embora sua inclusão como beneficiário seja uma das condições para sua realização, mas a cidadania envolve também ações em direção à informação, educação, cultura, entre outras, implicando o desenvolvimento da capacidade de refletir, analisar, decidir, de mobilizar-se e de participar pelo bem comum.

Mas para cumprir essa dimensão educativa em uma perspectiva emancipatória, não se deve restringir a responsabilizar as famílias, ou a ensiná-las a gerir seus conflitos, seus parcos recursos, sua vida, como se tudo dependesse de um processo de racionalização e planejamento, de cumprimento de papéis e normas e não de carências coletivas. Logo, evitar essa dimensão disciplinadora, e levar as famílias a refletir sobre sua realidade, a conhecer serviços e recursos do território, a mobilizar-se e a incluir-se em processos organizativos, coletivos na busca de garantia dos direitos.

Entendemos que no CRAS o Serviço Social é parte integrante da equipe básica, e se instalou na perspectiva de um trabalho interdisciplinar, em busca do protagonismo e do empoderamento da população atendida, com a perspectiva do trabalho com as famílias, atividades relacionadas ao PAIF-Serviço de Atendimento Integral a Família.

O trabalho com as famílias, referenciadas no território de abrangência do CRAS, privilegia a dimensão socioeducativa da política de Assistência Social na efetivação dos direitos relativos às seguranças sociais afiançadas. Assim, as ações profissionais relacionadas aos serviços prestados no CRAS devem provocar impactos na dimensão da subjetividade política dos usuários, tendo como diretriz central a construção do protagonismo e da autonomia na garantia dos direitos com superação das condições de vulnerabilidade social e potencialidades de riscos (MINISTÉRIO DO DESENVOLVIMENTO SOCIAL, 2006, p. 13).

O gráfico 05 demonstra a opinião dos jovens sobre mudanças de vida depois que começaram a participar dos programas do CRSS. Oito responderam sim, um respondeu não, que não mudou em nada e um não soube responder. 
Gráfico 5 - Opinião dos jovens sobre mudanças de vida.

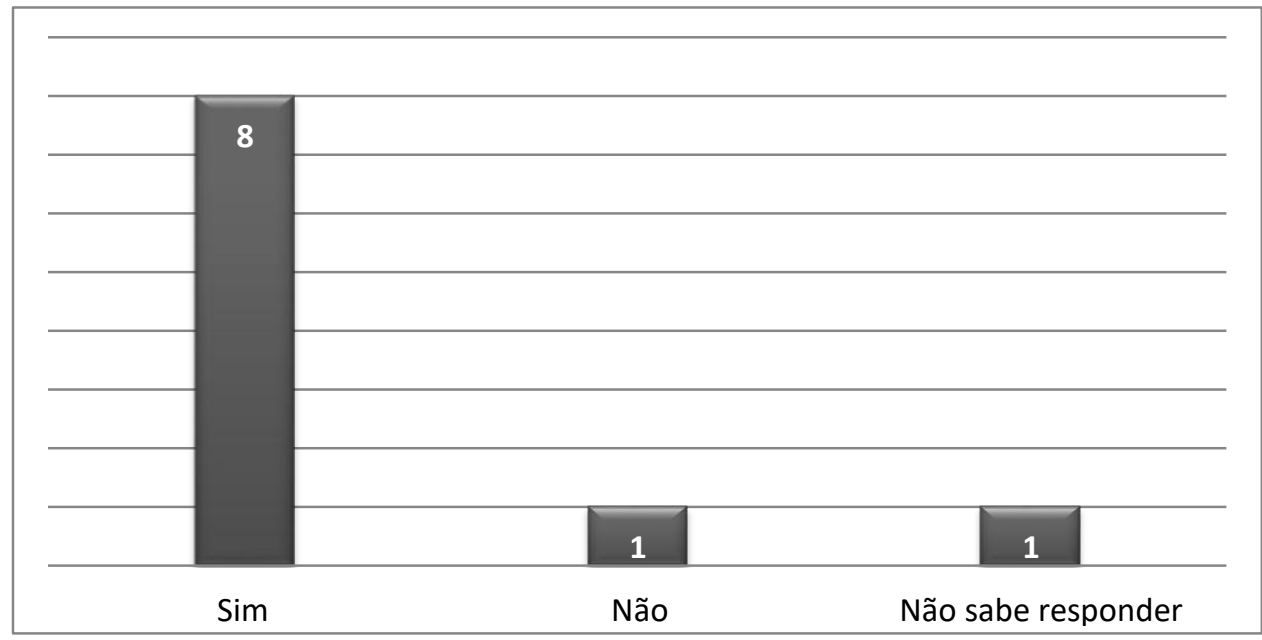

A constituição de espaço de convivência, formação para a participação e cidadania, desenvolvimento do protagonismo e da autonomia das crianças e adolescentes a partir de interesses, demandas e potencialidades dessa faixa etária. Estabelece ainda que as intervenções devem ser pautadas em experiências lúdicas, culturais e esportivas como formas de expressão, interação, aprendizagem, sociabilidade e proteção social.

Entende-se que o Serviço deve incluir crianças e adolescentes com deficiência, retirados do trabalho infantil ou submetidos a outras violações de direitos. Aos usuários, deve oferecer atividades que contribuam para ressignificar vivências de isolamento e de violação dos direitos, propiciando experiências favorecedoras do desenvolvimento de sociabilidades e atuando no sentido preventivo de situações de risco social.

À obrigatoriedade do Poder Público em ofertar o Serviço corresponde um compromisso da família com a inserção e permanência da criança ou adolescente. A frequência nas atividades deve ser entendida como elemento de proteção e de enfrentamento ao trabalho infantil, além de prevenção de sua reincidência. Constitui-se, portanto, na garantia do direito da criança/ adolescente à convivência, ao desenvolvimento integral e à proteção de assistência social (que se amplia para a família também).

De acordo com o Traçado Metodológico do PROJOVEN Adolescente - Serviço Socioeducativo, o convívio é parte da dinâmica social na qual se desenvolve o sentimento de pertença, a construção da identidade e a afirmação da individualidade. Por meio dele se realiza 
Id on Line Revista Multidisciplinar e de Psicologia

Id on Line Multidisciplinary and Psycology Journal

a transmissão dos códigos sociais e culturais e se estabelecem os valores que norteiam a vida em sociedade.

É também por meio do convívio que se estabelecem e se solidificam os vínculos humanos, inicialmente no âmbito familiar, constituindo uma rede primária de relacionamentos que asseguram afeto, proteção e cuidados e, posteriormente, nos espaços comunitários, ampliando-se o leque destes relacionamentos e tecendo-se redes secundárias, essenciais ao desenvolvimento afetivo, cognitivo e social. A segurança sentida na convivência familiar e comunitária oferecerá as bases necessárias para o amadurecimento e para a constituição de uma vida adulta saudável (MDS e SEDH, 2006).

Nesse sentido, esse eixo trata dos aspectos ligados aos espaços de convivência e seu potencial de viabilização da superação das vulnerabilidades sociais mediante um processo de construção e fortalecimento dos vínculos relacionais e de pertencimento que promovam a proteção e a garantia de direitos. Trata, também, dos aspectos relacionados às contradições e aos conflitos que permeiam as relações de convivência familiar e comunitária, e como estes interferem na construção e no fortalecimento de vínculos.

\section{Entrevistas com as famílias do CRAS}

Nos século XX, família era considerada pela sociedade aquela composta por pai, mãe e filhos, ou seja, o núcleo familiar. Sua relação era baseada na ideia em que o mundo externo é o espaço masculino, sendo o homem considerado o provedor econômico. E o espaço feminino, a casa e a educação dos filhos. As famílias que não se encaixavam nesse contexto, eram tidas como desestruturadas, sendo responsabilizadas por problemas morais e educacionais de seus membros.

Com a Constituição Federal 1988 art. 226 parágrafo 4' ' 'a família passa a ser entendida como a comunidade formada por qualquer dos pais e seus descendentes", passa a se reconhecer a existência da família monoparental. Essa formação de família rompeu com a ideia preconcebida de que a família deve ser compreendida como pai, mãe e filhos. Com a constituição o casamento deixou de ser o eixo fundamental da família. Independentemente da existência do casamento civil ou religioso, é considerada como entidade familiar a união estável entre homem e mulher. De acordo com o Código Civil Art. 1.723. 
É reconhecida como entidade familiar a união estável entre o homem e a mulher, configurada na convivência pública, contínua e duradoura e estabelecida com o objetivo de constituição de família.

Segundo Gomes (1998) a família é pensada como "um grupo de pessoas, vivendo numa estrutura hierarquizada, que convive com a proposta de uma ligação afetiva duradoura, incluindo uma relação de cuidado entre os adultos e 25 deles para com as crianças e idosos que aparecem nesse contexto".

Neste momento apresenta-se a pesquisa realizada sobre o cotidiano das famílias no CRAS em estudo. Segundo Netto (1987) o cotidiano profissional refere-se ao lugar onde a reprodução social acontece por meio de reprodução dos indivíduos, e por isto e um espaço ineliminável e insuprimível. "É no cotidiano que o assistente social exerce sua instrumentalidade com capacidade, qualidade para objetivar suas finalidades". (GUERRA, 2000, p.1).

Entendemos que no CRAS o Serviço Social é parte integrante da equipe básica, e se instalou na perspectiva de um trabalho interdisciplinar, em busca do protagonismo e do empoderamento da população atendida, com a perspectiva do trabalho com as famílias, atividades relacionadas ao PAIF-Serviço de Atendimento Integral a Família.

\footnotetext{
O trabalho com as famílias, referenciadas no território de abrangência do CRAS, privilegia a dimensão socioeducativa da política de Assistência Social na efetivação dos direitos relativos às seguranças sociais afiançadas. Assim, as ações profissionais relacionadas aos serviços prestados no CRAS devem provocar impactos na dimensão da subjetividade política dos usuários, tendo como diretriz central a construção do protagonismo e da autonomia na garantia dos direitos com superação das condições de vulnerabilidade social e potencialidades de riscos (MINISTÉRIO DO DESENVOLVIMENTO SOCIAL, 2006, p. 13).
}

Para compor a amostra da presente pesquisa foram selecionadas do Formulário de Atendimento Social do CRAS dez famílias atendidas pela assistente social para responder as perguntas do questionário

Os dados do formulário mostram que das dez famílias pesquisadas: uma com 1 membro; duas com 2 membros; três com 3 membros; duas com 4 membros; uma com 5 membros: uma com o membros. Em média são 4 membros por família. 
Id on Line Revista Multidisciplinar e de Psicologia

Id on Line Multidisciplinary and Psycology Journal

Segundo Medeiros e Osorio (2000) no que se refere a diminuição do tamanho da família, em um período de 30 anos de 1978 a 1998, a acentuada queda da taxa de fecundidade constitui o fator mais importante.

$\mathrm{Na}$ análise dos dados da segunda pergunta, cinco eram famílias monoparentais, composta pela mãe e seus filhos ou somente o pai e seus filhos; duas eram famílias nucleares, composta pelo casal e seus filhos; uma era família unipessoal composta por uma pessoa; uma era família extensa, composta pela família nuclear e seus parentes; e duas eram famílias recompostas, composta por padrasto, madrasta e filhos. Diante disso esses novos arranjos familiares expressam as transformações nas bases sócio-familiares na contemporaneidade De acordo com IBGE (2010, p. 12),

\begin{abstract}
Em relação às famílias, na comparação entre 2000 e 2010, houve um crescimento na proporção de unidades domésticas unipessoais (domicílios com um só morador), que passaram de $9,2 \%$ para $12,1 \%$. No Brasil, predominavam, em 2010, as famílias de duas ou mais pessoas com parentesco (54,3 milhões). Além disso, verificou-se uma aumento na proporção de famílias sob responsabilidade exclusiva da mulher $(22,2 \%$, em 2000, contra $37,3 \%$ em 2010)
\end{abstract}

Quanto ao nível da escolaridade dos membros das famílias, foi constatado que $40 \%$ possuíam o ensino fundamental incompleto; $20 \%$ o ensino fundamental; $5 \%$ o ensino médio incompleto; $5 \%$ o ensino médio completo; $10 \%$ o ensino superior incompleto; $1 \%$ o ensino superior completo; $10 \%$ analfabetos; $9 \%$ criança sem idade escolar.

Esses dados nos mostram que quase a metade das famílias atendidas possui o ensino fundamental incompleto, percebe-se também o baixo índice de analfabetismo conforme consta o censo 2010 do o IBGE que nos últimos dez anos (2000 a 2010) houve uma queda índice de analfabetismo. Em 2000 o número de analfabetos correspondia a 13,63\% da população de 15 anos ou mais de idade, e em 2010 esse índice caiu para 9,6\%. Essa queda deve-se ao investimento que o governo tem dado á educação através de programas como bolsa escola que tem como condicionalidade ao beneficiário manter seus filhos na escola. O Programa Bolsa Escola que tem o objetivo de tirar as crianças de trabalho infantil e o Programa Brasil Alfabetizado que são realizados em municípios com alto índice 34 de analfabetismo, Programa de Educação de Jovens e Adultos (EJA) destinado a jovens e adultos. 
Id on Line Revista Multidisciplinar e de Psicologia

Id on Line Multidisciplinary and Psycology Journal

A baixa escolaridade se reflete na análise da situação trabalhista das famílias atendidas mostrando que dois estavam empregados com carteira assinada; três estavam desempregados; Quatro estavam atuando na informalidade; dois recebiam benefícios assistenciais.

Considerando principalmente no nível formal as atuais exigências do mercado de trabalho pode-se entender a dificuldade dessas famílias no acesso ás oportunidades de uma ocupação formal, sendo obrigadas a atuarem na informalidade, ou permanecerem desempregados.

De acordo com Mattoso (1999) nos anos 90 o Brasil perdeu 3,3 milhões de postos de empregos formais numa realidade de 18 milhões de assalariados num total de 70 milhões da população economicamente ativa.

O Serviço Social conforme já mencionado tem na questão social a base da fundação como especialização do trabalho (IAMMAMOTO, 2009). E nos atendimentos á família tem como princípio básico enfatizar a efetivação dos direitos a serem garantidos por Lei.

De acordo com a lei 8662/93 artigo $4^{\circ}$ são competências do assistente social. Encaminhar providências e prestar orientação social a indivíduos, grupos e a população; orientar indivíduos e grupos de diferentes segmentos sociais no sentido de identificar recursos e de fazer uso dos mesmos no atendimentos e na defesa de seus direitos.

As ações dos assistentes sociais são em direção a prevenção de riscos sociais, e no combate a situações de vulnerabilidade social, financeira, fragilidade de vínculos e principalmente no regate da auto estima e ampliação do acesso aos direitos de cidadania.

Para que pudéssemos identificar as percepções das famílias sobre os serviços do CRAS, apenas cinco das dez responderam ás perguntas feitas na entrevista. Ao serem questionadas sobre o entendimento em relação ao CRAS, as famílias o relacionam como sendo algo bom, que ajuda. De acordo com algumas falas:

Pra mim o CRAS é um Programa do Bolsa Família, as pessoas vão lá (no CRAS) procurar ajuda é isso que eu sei. (F1)

É uma coisa muito boa para as famílias, muitas pessoas procuram por eles (equipe), e são bem atendidos. O CRAS é pra ajudar as famílias carentes, que quando não têm condições, vão procurar o CRAS para serem ajudadas. (F2)

O CRAS é pra tudo que a gente precisa. A gente vai lá pra tudo. (F3). 
Id on Line Revista Multidisciplinar e de Psicologia

Id on Line Multidisciplinary and Psycology Journal

Em primeiro lugar é o CRAS, tudo que a gente precisa, eles estão disposto pra ajudar apesar de que não entendo muita coisa. (F4)

[...] eu nem sabia que existia o CRAS. Quando eu estava passando por uma dificuldade, bem grande financeiramente, eu fui até ali (CRAS) e falei com a assistente social. E ela me fez algumas perguntas, e respondi sobre a minha vida, o que estava passando. E me ajudou bastante. Desde então o CRAS tem sido de grande benefício, não só pra mim, mas para a minha família também. (F5).

Diante das respostas das famílias entrevistadas identifica-se que as famílias não têm um conhecimento claro sobre o CRAS. Sendo a assistência social constituída como direito do cidadão e dever do Estado, ainda na percepção das famílias está relacionado ao assistencialismo.

Quanto ao conhecimento das famílias sobre o trabalho do assistente social, elas não destacam qual é o trabalho realizado, mas sim o que acham do trabalho. $\mathrm{O}$ trabalho do assistente social é entendido pelas famílias como ajuda resgate, coisa boa e de prestar assistência a famílias carentes.

E ao serem questionadas sobre suas percepções de como é o trabalho do assistente social, elas responderam que acham que é bom, ótimo, coisa boa, ajuda.

Eu acho que é bom tem muitas crianças e famílias precisando deles. (F1).

Na minha opinião pela [assistente social] que eu fui atendida foi ótimo (F2)

Pra mim só vou ao CRAS, quando preciso resolver problemas no meu cartão do Bolsa Família. (F3)

É pra ajudar as famílias, ela me ajudou nos cartões e também nos meus documentos (F4).

Eu participo do CRAS, mas não vejo muita mudança na minha vida não. Pelo menos tem o cartão do Bolsa Família, que serve pra ajudar as famílias. (F5)

Percebe-se que as famílias expressam em suas falas não terem muito entendimento sobre os serviços ofertados, assim como em algumas falas não percebem muita mudança em suas vidas, mas reconhecem que o trabalho do CRAS, é importante ressaltando a importância do incentivo do Bolsa Família, assim como o trabalho do assistente social mais numa visão de assistencialismo. As famílias não têm nenhum entendimento que o trabalho do assistente social visa à defesa e garantia de direitos sociais e não um trabalho de ajuda, bondade e caridade. Historicamente a ajuda perpassa nas manifestações da prática do assistente social desde suas expressões caritativas desenvolvidas pela igreja católica a filantropia estatal. 
E no Serviço de Convivo e Fortalecimento de Vínculos o trabalho tem objetivo de informar, incentivar e motivar a participação das famílias a atuarem em conjunto em direção a enfrentar as vulnerabilidades e fragilização dos vínculos apresentados por elas.

No que se refere às dificuldades encontradas no trabalho como a falta de rede que atenda todas as demandas, o número reduzido da equipe técnica a falta de qualificação e recursos financeiros, estruturas físicas inadequadas para a realização das atividades de grupo e área muito abrangente do CRAS, falta de transportes para deslocar os técnicos até essas áreas é ineficiente o profissional tem feito o que está ao seu alcance. Mesmo com várias dificuldades em realizar o trabalho, o assistente social tem estabelecido suas ações em prol da defesa e garantia dos direitos sociais das famílias vulneráveis.

Verifica-se que as famílias atendidas pela assistente social no CRAS não entendem que a assistência social constituída como direito do cidadão e dever do Estado, mas na percepção delas está relacionado ao assistencialismo. O trabalho do assistente social é compreendido pelas famílias como ajuda resgate, coisa boa e prestar assistência ás famílias carentes. Entendemos que o trabalho do Serviço Social tem sido em defesa e garantias dos direitos sociais dos indivíduos e famílias.

\section{Considerações Finais}

Conforme o conteúdo apresentado nesta dissertação foram feitas algumas inferências e considerações sobre o tema abordado. É plausível reconhecer a proteção social como responsabilidade estatal e dever de diversas políticas públicas, cabendo à política de Assistência Social realizar parte de sua execução. Essa responsabilidade comumente, em primeira instância, é atribuída às políticas públicas de seguridade social e, posteriormente, às demais políticas sociais.

Entretanto isso deveria ocorrer de modo diferenciado se o escopo da seguridade social fosse ampliado com a introdução das demais políticas que se comprometem com a proteção social. Logo, pode-se entender que um dos maiores desafios, senão o maior, posto às políticas públicas, no que diz respeito à proteção social, é pensá-la e implementá-la no âmbito da 
Id on Line Revista Multidisciplinar e de Psicologia

Id on Line Multidisciplinary and Psycology Journal

intersetorialidade, de modo que seja possível responsabilizar os diversos atores que deveriam se empenhar em sua condução.

Além disso, as expressões da questão social que perpassam a vida desses cidadãos são multifacetadas e exigem soluções igualmente plurais. Apesar de ser declarada como política de responsabilidade estatal, a Assistência Social ao compartilhar o seu campo de atuação com o Terceiro Setor, cria um movimento antagônico em seu formato, à medida que se afirma como Estatal e permite a sua execução por meio de entidades privadas sem fins lucrativos, que também são designadas como públicas, mas não Estatais. Dessa forma, atribui ações e perspectivas ao que não é Estado como se o fosse. Em consequência disso, contemplamos um modo precário, limitado e residual de se fazer política pública.

Para a efetivação de uma política pública de Assistência Social que cause impactos reais na sociedade, é de fundamental importância, conforme trabalhado neste projeto, o rompimento com o sufixo vicioso das políticas sociais. Para isso, é necessário que os profissionais que nela atuam conheçam o seu atual formato e revisitem constantemente as diversas produções críticas disponíveis sobre o assunto. Mais do que reformar a Assistência Social, urge a continuidade do processo de rompimento com as velhas práticas, pois realizar a nova política fundamentando-se nelas é torná-la inoperante e residual.

Contudo, sabe-se que o capitalismo como modelo econômico torna improcedente qualquer esforço que as políticas sociais isolada ou conjuntamente realizem para a transformação da sociedade. Não existe sociedade capitalista justa e igualitária e, sendo assim, esses objetivos só podem ser alcançados com o fim desse regime, todavia cabe não somente aos profissionais, mas também a cada cidadão desenvolver a consciência de classe para si que fomentará um novo projeto classista, capaz de emancipar os sujeitos sociais, sejam eles usuários ou não da política de Assistência Social.

A Proteção Social Básica deve ser entendida como um conjunto de ações e serviços que visem produzir impactos na realidade social de forma a proteger, promover e prevenir os seus usuários e aqueles que estão incluídos no seu grupo de relações, de modo a evitar a fragilização e rompimento de seus vínculos.

Para isso, é necessário que as práticas profissionais estejam alinhadas à macroestrutura societal, como também com à subjetividade de seus sujeitos. Uma política pública que despreza 
Id on Line Revista Multidisciplinar e de Psicologia

Id on Line Multidisciplinary and Psycology Journal

os elementos macrossociais ou a subjetividade dos usuários que por ela são atendidos torna-se incapaz de produzir impactos significativos sobre as suas vidas e o ambiente que os circunda.

O CRAS, como equipamento central da Assistência Social, tem a responsabilidade de ser um dos instrumentos de proteção social às famílias no território. É importante ressaltar que na política pública de Assistência Social, é ele que tem essa responsabilidade, sem deixar de lembrar que no escopo das demais políticas públicas, principalmente as de seguridade social, deve haver ações e serviços que objetivem assegurar a proteção social tanto em nível básico como em nível de especialidade.

Diante das tendências do trabalho social nos CRAS, é possível dizer que, apesar de os avanços conceituais da política de Assistência Social, principalmente do enfoque da pobreza e da articulação de respostas em benefícios, serviços, atenções e procedimentos variados, de atendimento individualizado e coletivo, e entre as políticas setoriais, o trabalho socioeducativo não superou ainda a psicologização dos problemas sociais, o trato de problemas internos à família e de sua responsabilização por estes.

A realidade empírica demonstra que não se efetiva uma metodologia de trabalho com famílias que, de fato, aborde, de forma dialética e articulada, assuntos internos e externos à família, sem hipertrofiar um dos polos e sem cair em modelos psicossociais individualizantes, ou seu oposto, os generalistas de transformação social, sem soluções práticas para o dia a dia.

Trabalhar dialeticamente as questões internas e externas às famílias, de forma articulada e numa perspectiva de totalidade, é o grande desafio do trabalho interdisciplinar, como recomendação de "não dar à questão social um tratamento de exterioridade à vida pessoal cotidiana" (SAWAYA apud CAMPOS, 2004, p. 33), mas sem supervalorizar as questões subjetivas ou internas às famílias, cujo objetivo deve ser sempre o alargamento da percepção das situações pessoais e sociais e a luta pela garantia dos direitos.

O trabalho socioeducativo com famílias ou grupos de famílias, bem como os procedimentos individuais de acolhimento, escuta qualificada, encaminhamentos e acompanhamentos devem buscar a inserção desses sujeitos no circuito do território e da rede de segurança social e articular o individual e o familiar no contexto social, levando esses sujeitos a ultrapassar o imediatismo de suas concepções, mas tendo como princípio que subjetividades transformadas só provocam mudanças com ações coletivas, com acesso a serviços, benefícios, ou seja, com condições objetivas. 
Id on Line Revista Multidisciplinar e de Psicologia

Id on Line Multidisciplinary and Psycology Journal

Todavia, só o acesso a serviços e benefícios como dádiva, benesse, caridade não provoca mudanças subjetivas políticas, autonomia e cidadania, mas sim subalternidade e tutela.

É nesse sentido que se precisam romper as dicotomias e unir conhecimentos específicos ideal, se na mesma perspectiva teórica e metodológica, para o trabalho interdisciplinar, guiados por uma perspectiva de totalidade que: Supere a psicologização das relações e problemas sociais ultrapasse a dimensão conservadora, disciplinadora, normatizadora e, principalmente, de julgamento, culpabilização das famílias pelo não cumprimento de funções tradicionalmente e funcionalmente atribuídas às famílias; procure romper com os referenciais teóricos funcionalistas das famílias 'desestruturadas', 'disfuncionais', incompletas pelo não atendimento ao modelo padrão, ideal de família; ultrapasse o âmbito da realidade familiar e do território, para entendê-los como inseridos em determinações mais amplas, parte de um todo, o que leva ao entendimento de que os problemas e dificuldades familiares são decorrentes de múltiplos processos sociais; fortaleça a dimensão preventiva dos problemas sociais, atuando em dificuldades cotidianas, buscando dar sustentabilidade à família, suporte, apoio, cuidados, serviços e ações outras necessárias para não chegarem a vivenciar situações extremas, o que pressupõe o Estado assumir responsabilidade pública pelo atendimento de suas necessidades; articular serviços e/ou, criar novos serviços, projetos e programas para atender as necessidades e demandas levadas pelas famílias.

Diante do estudo de pesquisa realizado observou-se que muitas são as barreiras e problemas que afetam as famílias pesquisadas, problemas esses que perpassam os espaços do CRAS e do lócus familiar, os mesmos apresentados em capítulos anteriores por sua vez apresentam questões que desafiam os técnicos da política de assistência social, pois muitas dessas famílias também necessitam da assistência e articulação de outras políticas públicas entre elas: saúde, educação, assistência jurídica, entre outras demandas. Espera-se que os serviços e programas ofertados no CRAS, possam desenvolver melhores alternativas e estratégias voltadas para o alcance da autonomia e protagonismo dessa famílias, bem como a ampliação dos investimentos por parte das três esferas de governo melhorando as ofertas de serviços, melhoria de estruturas físicas, mais suporte técnico, incentivos financeiros para os profissionais e toda equipe técnica.

Se há alguma falha nesse processo, pode ser atribuída a algumas das políticas que se eximem de computar sua parcela de participação. Entretanto, com isso não se quer afirmar que 
Id on Line Revista Multidisciplinar e de Psicologia

Id on Line Multidisciplinary and Psycology Journal

a Assistência Social não precise ser potencializada, mas sim reiterar que a discussão sobre a proteção social deveria girar em torno dos limites que a setorialidade impõe para a sua execução. É mais do que urgente reconhecer que a proteção social só alcançará o seu objetivo se realizada por meio de uma lógica intersetorial, o que quer dizer ir além de discutir agendas programadas e pactuadas isoladamente.

Diante de toda realidade chega-se à conclusão, que todas essas questões interferem diretamente na vida social e na relação interpessoal desses indivíduos impossibilitando-os de alcançarem o seu desenvolvimento de maneira a conquistar sua autonomia profissional, e consequentemente o seu protagonismo. Esperamos que esse trabalho subsidie o debate sobre as Políticas de Assistência Social, melhorando a qualidade e a oferta dos serviços junto a essas famílias mais vulneráveis, bem como as reflexões sobre o fazer profissional no CRAS.

\section{Referências}

ALENCAR, FS; CAVALCANTE, LVTF; LIMA, MS; OLIVEIRA, NS; OLIVEIRA, GF. Atendimento domiciliar em saúde mental ao usuário do CAPS. Id on line Revista de Psicologia, 7 (21), 85-93, 2013.

ALVES, José Augusto Lindgren. Cidadania, Direitos Humanos e Globalização. Direitos Humanos, Globalização Econômica e Integração Regional: desafios do Direito Constitucional Internacional. São Paulo: Max Limonad, 2002.

BLUMER, H. (1982). El interaccionismo simbolico: perspectiva y metodo. Barcelona: Hora. (Trabalho publicado em 1969).

BRANCO, Francisco, 2001, A face lunar dos direitos sociais - virtualidades e limites do RMG como direito de cidadania em Portugal, tese de Doutoramento em Serviço Social, São Paulo: Pontifícia Universidade Católica São Paulo.

BRASIL. Conselho Nacional de Assistência Social. Resolução no109, de 11de novembro de 2009. Brasília, 2009.

BRASIL. Ministério do Desenvolvimento Social e Combate à Fome. Norma Operacional Básica do Sistema Único de Assistência Social (NOB-SUAS). Brasília: MDS, 2005.

BRASIL. Ministério do Desenvolvimento Social. Plano Nacional de Promoção, Proteção e Defesa do Direito de Crianças e Adolescentes à Convivência Familiar e Comunitária Presidência da República. Brasília: SEDH/ MDS/ CONANDA, 2006. 
Id on Line Revista Multidisciplinar e de Psicologia

Id on Line Multidisciplinary and Psycology Journal

BRASIL. Política Nacional de Assistência Social. Ministério do desenvolvimento social e combate a fome: Secretaria Nacional de Assistência Social. Brasília, 2004.

CAMPOS, André. O enfrentamento da pobreza brasileira nos anos recentes. Revista de Políticas Públicas. V. 9, p. 229-249, jan./jun. 2005.

CASTRO, F. J. R. O CRAS nos Planos de Assistência Social: padronização, descentralização e integração. In: Capacitações Suas. v. 3. São Paulo: IEELPUC-SP; Brasília: MDS, 2008.

CRISPIM, Mira. Cala a Boca, Jornalista”. São Paulo: Editora Vozes. 4. ed., 1992. p. 182.

DEMO, Pedro. Pesquisa: princípios científico e educativo. São Paulo: Cortez, 1989.

CRAS - Centro de Referência de Assistência Social. Caderno. 2009.

DESENVOLVIMENTO HUMANO (2000). Disponivel em: http://www.pnud.org.br/IDH/Default.aspx?indiceAccordion=1\&li=li_AtlasMunicipios. Acessado em 12 de Jan de 2016.

ESTATUTO DA CRIANÇA E DO ADOLESCENTE- ECA (1990). Lei no 8.069, de 13 de julho de 1990. Centro de Documentação e Informação Coordenação de Publicações, Brasília.

FALEIROS, Vicente de Paula. Estratégias em Serviço Social. 5 ed. São Paulo: Cortez, 2005.

FALEIROS, Vicente de Paula. Fome, pobreza e exclusão social: desafios para o governo e a sociedade. Ser Social. Brasília, n. 13, p. 109-130, jul./dez. 2003.

FREIRE, Paulo. Pedagogia da Autonomia: saberes necessários à prática educativa . Rio de Janeiro: Paz e Terra, 1997.

GIL, A. C. Métodos e técnicas de pesquisa social. São Paulo: Atlas, 1999/2006.

GOMES, Ana Lígia. Os conselhos de políticas e de direitos. In Universidade Nacional de Brasília. Centro de Educação Aberta, Continuada, A Distância. Capacitação em serviço social e política social: módulo 4: o trabalho do assistente social e as políticas sociais. Brasília, 1998, p.162-172.

GROENINGA, Giselle Câmara; PEREIRA, Rodrigo da Cunha. Direito de Família e psicanálise Rio de Janeiro: Imago... do Advogado n 123. Agosto de 2015.

GUERRA, Yolanda (orgs.). Serviço Social: Temas, Textos e Contextos. Coletânea Nova de Serviço Social. Rio de Janeiro: Editora Lúmen Juris. 1995/2000.

GUIMARÃES, R. F.; ALMEIDA, S. C. G. Família: Redes, Laços e Políticas Públicas. In Acosta, A. R. e Vitalle, M. A. F. (Orgs). Instituto de Estudos Espaciais, PUC - SP, São Paulo:

Cortez, 2007.

IAMAMOTO, Marilda Vilela. O Serviço Social na Contemporaneidade: Trabalho e Formação. 17.ed.São Paulo, Cortez,2009 
Id on Line Revista Multidisciplinar e de Psicologia

Id on Line Multidisciplinary and Psycology Journal

IAMAMOTO, Marilda Villela. Serviço Social em tempo de capital fetiche: capital financeiro, trabalho e questão social.3.ed.São P_aulo : Cortez, 2008.

IAMAMOTO, Marilda. CARVALHO, Raul. Relações Sociais e Serviço Social no Brasil. 18. ed. São Paulo: Cortez, 2005.

INSTITUTO BRASILEIRO DE GEOGRAFIA E ESTATÍSTICA- IBGE. Censo Demográfico 2010: Famílias e Domicílios e Nupcialidade, fecundidade e migração. Disponível em: http//www.Ibge.gov.br/home/estatística/população/censo2010. Acesso em: 05/02/2016.

LAKATOS, Eva Maria; MARCONI, Marina de Andrade e. Fundamentos de metodologia científica. 5. ed. São Paulo: Atlas, 2003.

MATTOSO, J. Instituto Brasileiro de Geografia e Estatística - IBGE. Censo Demográfico 1999.

MEDEIROS, M. e OSÓRIO, R.G. Revista Brasileira de Estudos de População, v.17, n.1/2, jan./dez. 2000

MIOTO, R. C. T. A centralidade da família na Política de Assistência Social: contribuições para o debate. In: Revista de Política Pública. São Luis: EDUFMA, v. 8, n. 1, jan. / jun. 2004.

MÜLLER, Friedrich. Que grau de exclusão social ainda pode ser tolerado por um sistema democrático?. Direitos Humanos, Globalização Econômica e Integração Regional: desafios do Direito Constitucional Internacional. São Paulo: Max Limonad, 2002, p. 568-596.

NETTO, J. P. A construção ético-politica do serviço social frente a crise contemporânea. Brasília, 1987/1996.

NÚNCIO, Maria José da Silveira, 2010, Introdução ao Serviço Social: história, teoria e métodos, Lisboa: Instituto Superior de Ciências Sociais e Políticas.

OLIVEIRA, Claudionor dos Santos. Metodologia científica, planejamento e técnicas de pesquisa: uma visão holística do conhecimento humano. São Paulo: LTR, 2001/2007.

OLIVEIRA, GF; ROLIM NETO, ML; REIS, AA; BIANCO, BAV. The Custody and Psychiatric Treatment in Brasil: A Systematic Review. Pensee Journal 76 (7), 116-139, 2014.

PARENTE, L. B. M. Participação Social como instrumento para a construção da democracia: a intervenção social na administração pública brasileira. Disponível em: http://portal2.tcu.gov.br/portal/pls/portal/ docs/769529.PDF. Acesso em: 2 set. 2015.

PASTORINI, Alejandra. A Categoria “Questão Social” em debate. 3. ed. São Paulo: Cortez, 2010.

PEREIRA, L. Exclusão Social e Fragilização da Identidade em Famílias Pobres. Trabalho apresentado no Seminário Família e Comunidade: Justiça Social, promovido pelo curso de Psicologia, Unicentro Newton Paiva e AMITEF, Belo Horizonte, 2000.

PIMENTEL, Edlene. Uma "Nova Questão Social"? Raízes Materiais e Humano-Sociais do Pauperismo de Ontem e de Hoje. Maceió: UFAL, 2007. 
Id on Line Revista Multidisciplinar e de Psicologia

Id on Line Multidisciplinary and Psycology Journal

REALE, Giovanni e Antiseri, Dario. História da Filosofia, vol II. São Paulo: Paulus, 1999.

SAWAYA, B. B. Que família é essa" In: WANDERLEY, M. B; OLIVEIRA, I. C. (Org.). Trabalho com famílias: textos de apoio, v. 2, São Paulo: IEE-PUC-SP, 2004.

SAWAYA, B. B., \& CAMPOS, M. C. C. Possibilidades abertas pelp Programa Fortalecendo a Família - PFF/SP/SP. In: WANDERLEY, M. B; OLIVEIRA, I. C. (Org.). Trabalho com famílias: textos de apoio, v. 2, São Paulo: IEE-PUC-SP, 2004.

SAWAYA, B. B., \& CAMPOS, M. C. C. Saúde mental e estrutura familiar: o lugar do sofrimento psíquico grave. Dissertação de Mestrado. Brasília: UnB, 2007.

SILVA E SILVA, Maria Ozanira. Os programas de transferência de renda e a pobreza no Brasil: superação ou regulação?. Revista de Políticas Públicas. v.9, n.1, p. 251-278, jan./jun. 2005.

SILVA, Maria Ozanira da Silva e (Coord.). O Serviço Social e o Popular: resgate teóricometodológico do projeto profissional de ruptura. 6. ed. São Paulo: Cortez, 2009.

SOUSA, Charles Toniolo de. A prática do assistente social: conhecimento, instrumentalidade e intervenção profissional. Emancipação, 8(1): 119-132 Ponta Grossa:UEPG, 2008.

SPOSATI, Aldaíza, VASCONCELOS, M., et. al. A Assistência Social e a Trivialização dos Padrões de Reprodução Social. In: SPOSATI, A.; FALCÃO, M. do C.; FLEURY, S. M. Os Direitos (Dos Desassistidos) Sociais. 5 ${ }^{\text {a }}$ ed. SP: Cortez, 2006.

SPOSATI, Aldaíza. Modelo Brasileiro de Proteção Social Não Contributiva: Concepções e Fundamentos em Concepções e Gestão da Proteção Social Não Contributiva no Brasil. Brasília: Ministério do Desenvolvimento Social e Combate à Fome, UNESCO, 2009.

STEIN, Rosa Helena. Pobreza e desigualdade na América Latina sob o olhar dos organismos internacionais. Ser Social. Brasília, v.1, n.18, p. 79-125, jan./jun. 2006.

SUAS: Sistema Único de Assitência Social: manual informativo para jornalistas, gestores e técnicos. Brasília: Ministério do Desenvolvimento Social e Combate à Fome, 2005.

TEIXEIRA, Joaquina Barata. Concepção da dimensão política da prática profissional. In: ANAS. Serviço Social: as respostas da categoria aos desafios conjunturais. IV Congresso Brasileiro de Assistentes Sociais. Congresso Chico Mendes. 2. ed. São Paulo: Cortez, 1995.

TEIXEIRA, Solange Maria. Trabalho Interdisciplinar nos CRAS: um novo enfoque e trato à pobreza? Porto Alegre, Textos e Contextos, v.9, n. 2, p.286-297, ago./dez. 2010.

YAZBEK, Maria Carmelita. A pobreza e as formas históricas de seu enfrentamento. Revista de Políticas Públicas. São Luís, v.9, n.1, p. 217-227, jan./jun. 2005.

YAZBEK, Maria Carmelita. Questão Social: Desigualdade, Pobreza e Vulnerabilidade. In: IEE. Curso de Capacitação de Gestores Sociais. São Paulo: IEE, 2008. 


\section{Como citar este artigo (Formato ABNT):}

SOUZA, A.L.; ROCHA, L.M.N. Serviços de Convivência e Fortalecimento de Vínculos na Relação Família e Sociedade. Id on Line Revista Multidisciplinar e de Psicologia, Fevereiro de 2017, vol.11, n.34, p. 01-38. ISSN: 1981-1179.

Recebido: 08/02/2017

Aceito: 10/02/2017 